豊田 暢之* - 小玉 和寿* - 西村友貴子* 島影 雅史* ・ 竹内 資和* ・服部 岩和*

\title{
Miscibility and Properties in the Blends of Polypropylene with Hydrogenated Polystyrene-block-polybutadiene-block-polystyrene (SEBS)
}

Nobuyuki TOYODA, Kazuhisa KODAMA, Yukiko NISHIMURA, Masashi SHIMAKAGE, Motokazu TAKEUCHI and Iwakazu HATTORI (Elastomer Laboratory, Polymer Research Laboratories JSR Corporation, 100 Kawajiri-cho, Yokkaichi, Mie, 510-8552, Japan)

The properties, morphology, and miscibility of isotactic polypropylene (PP) blended with a series of hydrogenated polystyrene-block-polybutadiene-block-polystyrene (SEBS) were investigated using tensile test, transmission electron microscope(TEM), dynamic mechanical analysis (DMA), differential scanning calorimetry (DSC), pulse NMR. These copolymers were prepared by hydrogenation of anionically polymerized same amounts of polystyrenes and polybutadienes with controlled amounts of 1,2 addition (vinyl content) from 41 to 85\%. TEM images showed that the phase separated structures were independent of the vinyl content of the SEBS in the PP/SEBS=70/30 blends, and that the miscibility of the blend was increased with increasing the vinyl content of the SEBS. This structure improves the mechanical properties and transparency of the blends.

(Received on August 6, 2002) (Accepted on October 18, 2002)

Key Word : SEBS, Hydrogenated SBS, Miscibility, PP/SEBS blend, Vinyl content, Transparency

\section{1. 緒 言}

ポリプロピレン $(\mathrm{PP})$ は安価で，良好な物性のバランス を有し，成形加工性やリサイクル性に優れた材料として， 自動車, 家電，雑貨などの幅広い用途に用いられている. PPの欠点を改良するために，PP と他のポリマーをブレン ドする試みは数多く行われてきた1)，2)．結晶性のPPに異 種ポリマーをブレンドすると，PPの結晶性が大きく影響 を受け, 結晶の成長速度や大きさ, 高次構造等は異種ポリ マーとPP との相容性により大きく変化する，そのため, PP とブレンドするポリマーの相容性を研究することはPP アロイの性能を $100 \%$ 引き出すには重要なことである.

本報ではPP と, ポリスチレンーblockーポリブタジエンー block-ポリスチレン (SBS)を水素添加して得られる, ポリ スチレン-block-ポリ(エチレン-co-ブチレン)-block-ポリ スチレン (SEBS) との相容性を研究した. 特許等には高ブ チレンSEBS もしくは高ブチレン水添SBR と PP とをブレ

*JSR 侏高分子研究所 ( テ 510-8552 四日市市川尻町 100)
ンドすると, 配合物の硬度が下がり, 透明性が高くなるこ とが報告されているが詳細は不明である ${ }^{3-5)}$. SEBSの相容性に影響する因子として，分子量やブロック 構造, スチレン含量, ブチレン含量等が挙げられる. PP/ エチレン・ブチレン共重合体ブレンドでは, ブチレン含量 がブレンドの相容性に影響を与えることが報告されている 6)，7)。また，高ブチレン含量のSEBSがPP と相容するこ とが報告されている8-10). 本報ではSEBS の分子量やブ ロック構造, スチレン含量を統一し, ブチレン含量のみを 変量したSEBSを作製した。これらのSEBSとPPとのブ レンドの物性を評価し，ブチレン含量によって決定される 相容性とブレンドの物性との関係について論じる.

\section{2. 実験}

\section{1 試料およびブレンド物の作製}

本研究ではチッソ(株) 製 PPを(商品名K1016, MFR= $5 \mathrm{~g} / 10 \mathrm{~min}$ ) 使用した。 MFRはすべて温度 $230^{\circ} \mathrm{C}$, 荷重 21.2Nで測定した.

一連のSEBSはリビングアニオン重合により合成した. 
内容積 50 リットルのオートクレーブに，所定量の脱気・ 脱水したシクロヘキサン, テトラヒドロフラン, スチレン を仕込んだ後, $\mathrm{n}$ ーブチルリチウムを加え, $50{ }^{\circ} \mathrm{C}$ からの断 熱重合を行った. 反応液を $30^{\circ} \mathrm{C}$ とした後，1,3-ブタジエ ンを加え断熱重合を行った。モノマー転化率がほぼ100\% になった後，更にスチレンを加え重合を行った．重合が完

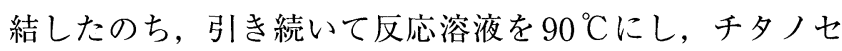
ン化合物を主体とした水添触媒を加え, 水素圧 $1.0 \mathrm{MPa}$ で 2 時間水添反応を行った．得られた水添ブロック共重合体 の水添率は $98 \%$ 以上, 重量平均分子量は 12 万前後, 水添 前ポリマーの結合スチレン含量は 15 重量\%, ブタジエン ブロックのビニル結合含量は $41 \sim 85 \%$ あった. ビニル 結合含量はテトラヒドロフラン添加量と 1,3-ブタジエンブ ロック重合時の反応開始温度を適宜変更して Table 1 に示 す一連のサンプルを得た. 本報ではSEBSのエチレン・ブ チレン共重合体ブロック成分におけるブチレン構造の重量 分率を水添前の構造と対応してビニル含量と呼ぶことにす る.

$\mathrm{PP}$ 単体および PP/SEBS ブレンドの評価用試験片は, 70\%のPPと $30 \%$ SEBSを，スクリュー径が $40 \mathrm{~mm}$ で，

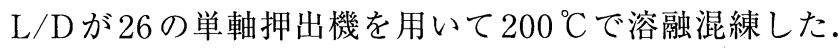
得られたペレットを型締力 100 トンの射出成形機を用い $\tau$, 成形温度 $200{ }^{\circ} \mathrm{C}$, 金型温度 $40^{\circ} \mathrm{C}$, 射出圧 $60 \mathrm{MPa}$, 背 圧 $3 \mathrm{MPa}$ で試験片を作製した。また，ホットプレスを用い， $200{ }^{\circ} \mathrm{C} ， 15 \mathrm{MPa}$ で作製したシートも評価用試験片とした.

\section{2 評価}

2.2 .1 力学物性 引張特性, 曲げ特性をそれぞれ, JIS-K7113，JIS-K7203に準拠して，3.2mm厚の射出成形 品を用いて測定した.

\section{2 .2 示差走査熱量(DSC)測定}

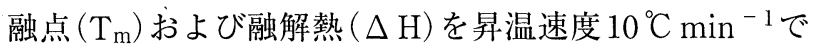
測定し，結晶化度 $\left(X_{C}\right)$ を $X_{C}=\frac{\Delta H}{\Delta H^{0}{ }_{P P}}$ により計算した。こ こで $\Delta H^{0}{ }_{p p}$ は結晶化度 $100 \%$ のP の融解熱を表し $\Delta H_{p p}^{0}=209 \mathrm{Jg}^{-1}$ である. ${ }^{11)}$

2.2.3 耐溶剤性 PP 単体, SEBS 単体, PP/SEBS ブ レンド試料の $2 \mathrm{~mm}$ 厚プレス成形品を $23{ }^{\circ} \mathrm{C}$ のルエンに浸 せきして 1 カ月後の表面状態の変化を目視で観察した.

\subsection{4 透明性(HAZE)}

JIS-K7105に準拠して $1 \mathrm{~mm}$ 厚のプレス成形品を用いて 測定した.

\section{2 .5 透過型電子顕微鏡 (TEM) 観察}

ブレンド物のモルフォロジーはTEMで観察した。射出 成形した試料の中央部の，観察面が流動方向と平行となる よう凍結ミクロトームを用いて切り出し, 四酸化ルテニウ ムを用いて染色して観察用超薄切片とした。 それを，(株) 日立製作所製 $\mathrm{H}-7500$ 型透過型電子顕微鏡を用いて観察し
Table 1 Characteristics of SEBS

\begin{tabular}{|c|c|c|c|c|c|c|c|}
\hline Sample & $\begin{array}{r}\text { Vinyl }^{*} \\
(\%)\end{array}$ & $\begin{array}{l}{ }^{1} \mathrm{M}_{\mathrm{w}}{ }^{* 2} \\
\left(\times 10^{4}\right)\end{array}$ & $\begin{array}{c}\text { Bound } \mathrm{ST}^{* 3} \\
(\%)\end{array}$ & $\begin{array}{l}\mathrm{T}_{\mathrm{B}} * 4 \\
(\mathrm{MPa})\end{array}$ & $\begin{array}{l}\mathrm{E}_{\mathrm{B}}{ }^{* 5} \\
(\%)\end{array}$ & $\begin{array}{c}\mathrm{MFR}^{* 6} \\
(\mathrm{~g} / 10 \mathrm{~min})\end{array}$ & $\begin{array}{l}\text { Hardness } \\
\text { (SHORE A) }\end{array}$ \\
\hline SEBS41 & 141 & 13 & 15 & 22 & 590 & 0.6 & 64 \\
\hline SEBS58 & $8 \quad 58$ & 12 & 15 & 18 & 700 & 4 & 54 \\
\hline SEBS68 & $8 \quad 68$ & 12 & 15 & 14 & 770 & 9 & 50 \\
\hline SEBS73 & $\begin{array}{ll}3 & 73\end{array}$ & 12 & 15 & 14 & 850 & 10 & 46 \\
\hline SEBS76 & $6 \quad 76$ & 12 & 15 & 14 & 850 & 10 & 44 \\
\hline SEBS79 & $\begin{array}{l}9 \\
9\end{array}$ & 11 & 15 & 13 & 870 & 30 & 42 \\
\hline SEBS85 & $5 \quad 85$ & 12 & 15 & 12 & 890 & 31 & 39 \\
\hline
\end{tabular}

た.なお，本ブレンド系では，PPよりもSEBSの方が強 く染色された.

\subsection{6 動的粘弾性(DMA)測定 ブレンド物の動的粘弾} 性特性を知るために, $1 \mathrm{~mm}$ 厚プレス成形品を用いて, 振 動周波数 $1 \mathrm{~Hz}$, 初期ひずみ $0.05 \%$, 昇温速度 $3{ }^{\circ} \mathrm{C}$ $\min ^{-1}$ の条件でDMA 測定を行った。

2.2.7 パルスNMR測定 ブレンド物の相分離構造を 核磁気共鳴緩和時間の差から知るために，ソリッドエコー 法によって ${ }^{1} \mathrm{H}$ 核のスピンースピン緩和時間 $\mathrm{T}_{2}$ を測定し た。測定条件はパルス系列 $90 \mathrm{x}-\tau 90 \mathrm{y}, \mathrm{RF}$ パルス幅 (Pw1) $2.0 \mu$ 秒，パルス間隔(Pi1) $10.0 \mu$ 秒，積算回数 32 回, 測定温度 $26{ }^{\circ} \mathrm{C}$ ，パルス系列繰り返し時間 3 秒である。得ら れた $\mathrm{T}_{2}$ 緩和曲線を最も緩和時間が短い成分をガウス関数 で，他の 2 成分はローレンツ関数を用いて非線形最小二乗 法で最適化し, 単位体積中の水素重量分率として求めた. $\mathrm{T}_{2}$ 緩和時間の短い方から順にそれぞれ $\mathrm{T}_{2 \mathrm{~S}}, \mathrm{~T}_{2 \mathrm{M}}, \mathrm{T}_{2 \mathrm{~L}}$ と した。

\section{3. 結 果と考 察}

\section{1 力学特性}

Table 1 には試作した一連のSEBSの分子特性と単体の 物性を示す.ビニル含量や重量平均分子量, スチレン含量 はほぼ同じである。しかし, SEBS単体の引張強度はビニ ル含量が増加するに従い小さくなり, 引張破断伸びは増加 している.

Table 2 にPP/SEBSブレンドの物性評価結果まとめて 示した. Fig. 1 にPP/SEBSブレンドの曲げ試験結果を示 す。ブレンド物の曲げ弾性率はビニル含量に依存し, 60\%以下では一定で，60\%以上ではビニル含量の増加と 共に低下した.SEBS 単体の硬度はビニル含量に対して単 調に減少するため，ビニル含量が $60 \%$ 以上のSEBSのみ がPPを軟質化する能力を有することを示唆した。

Fig. 2 にPP/SEBS ブレンドの引張試験結果を示す．引 
Table 2 Properties of PP and PP/SEBS blends

\begin{tabular}{lccccccc}
\hline Sample & $\begin{array}{c}\mathrm{F}_{\mathrm{M}}{ }^{* 1} \\
(\mathrm{MPa})\end{array}$ & $\begin{array}{c}\mathrm{T}_{\mathrm{B}} \\
(\mathrm{MPa})\end{array}$ & $\begin{array}{c}\mathrm{E}_{\mathrm{B}} \\
(\%)\end{array}$ & $\begin{array}{c}\mathrm{T}_{\mathrm{m}} \\
\left({ }^{\circ} \mathrm{C}\right)\end{array}$ & $\begin{array}{c}\Delta \mathrm{H} \\
\left(\mathrm{Jg}^{-1}\right)\end{array}$ & $\begin{array}{c}\mathrm{X}_{\mathrm{C}} \\
(\%)\end{array}$ & $\begin{array}{c}\text { Haze } \\
(\%)\end{array}$ \\
\hline $\mathrm{PP}$ & 1350 & 21.6 & 40 & 163.5 & 104.9 & 50 & 85 \\
$\mathrm{PP} / \mathrm{SEBS} 41=70 / 30$ & 850 & 19.9 & 100 & 160.4 & 66.1 & $45^{* 2}$ & 93 \\
$\mathrm{PP} / \mathrm{SEBS58}=70 / 30$ & 830 & 19.6 & 100 & 161.0 & 67.8 & $46^{* 2}$ & 97 \\
$\mathrm{PP} / \mathrm{SEBS68}=70 / 30$ & 680 & 20.2 & 190 & 160.4 & 64.7 & $44^{* 2}$ & 82 \\
$\mathrm{PP} / \mathrm{SEBS73}=70 / 30$ & 590 & 21.2 & 500 & 160.6 & 68.9 & $47^{* 2}$ & 69 \\
$\mathrm{PP} / \mathrm{SEBS76}=70 / 30$ & 530 & 20.5 & 570 & 161.2 & 68.0 & $46^{* 2}$ & 57 \\
$\mathrm{PP} / \mathrm{SEBS79}=70 / 30$ & 530 & 20.3 & 670 & 161.3 & 67.6 & $46 * 2$ & 41 \\
$\mathrm{PP} / \mathrm{SEBS} 55=70 / 30$ & 400 & 20.3 & 730 & 161.8 & 70.9 & $48^{* 2}$ & 39 \\
\hline$* 1$ & Flexural modulus & & & & & & \\
$* 2$ & per gram of PP & & & & & &
\end{tabular}

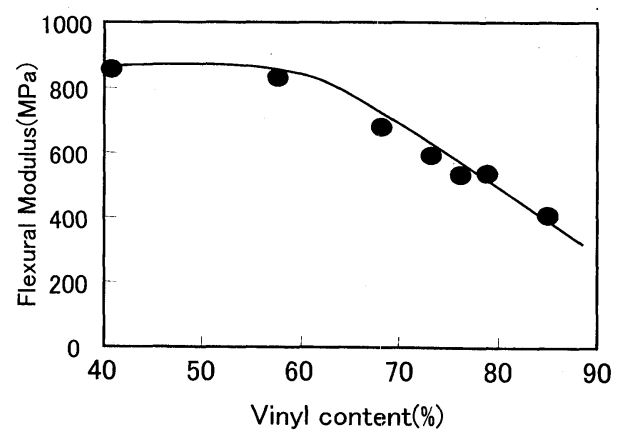

Fig.1 Plot of flexural modulus against the vinyl content of the SEBS in PP $/$ SEBS $=70 / 30$ blends.

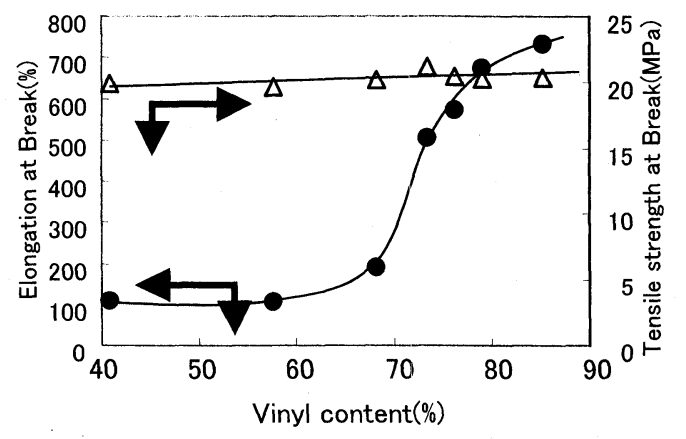

Fig.2 Plot of elongation at break (left : filled circle) and Tensile strength (right : open triangle) against the vinyl content of the SEBS in PP/SEBS $=70 / 30$ blends.

張破断伸びはビニル含量が $70 \%$ 以上で急激に向上した. しかし, SEBS単体の引張破断強度はビニル含量の増加と ともに減少するのに対して, ブレンド物の引張破断強度は ビニル含量にほとんど依存せず，PP単体と同等であった. 引張破断伸びおよび引張破断強度の結果から, $\mathrm{PP} /$ 高ビニ ルSEBSブレンドでは相分離構造の変化や補強効果が示唆 され, 詳細は後のモルフォロジー観察結果とともに述べる.

\subsection{PPの結晶性}

Fig. 3 にPP/SEBSブレンドの DSC曲線を示す。いずれ の系でも単体のPP と類似の曲線であることが分かる. Fig. 4 には得られたDSC曲線を解析して, PPの融点とPP 単位あたりの融解熱から求めた結晶化度, $X_{C}$ を示した. PPにSEBSを添加しても融点降下はほとんどなかった。 また，高ビニル SEBSブレンドでは $X_{C}$ はビニル含量が増

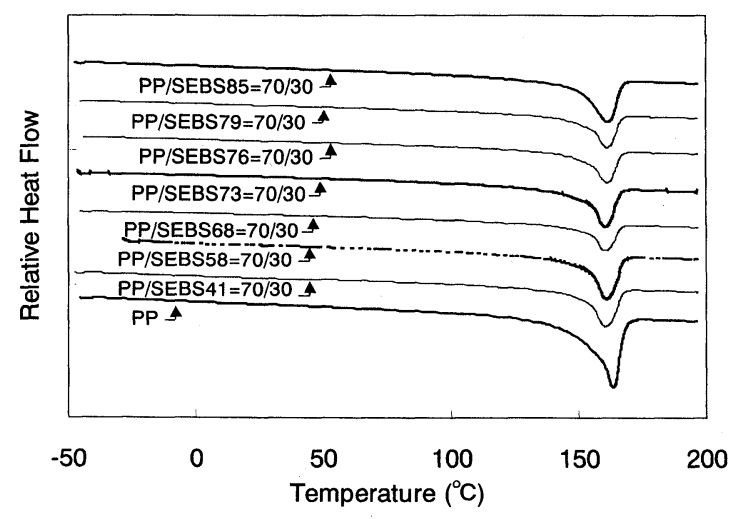

Fig.3 DSC curves of PP/SEBS $=70 / 30$ blends.

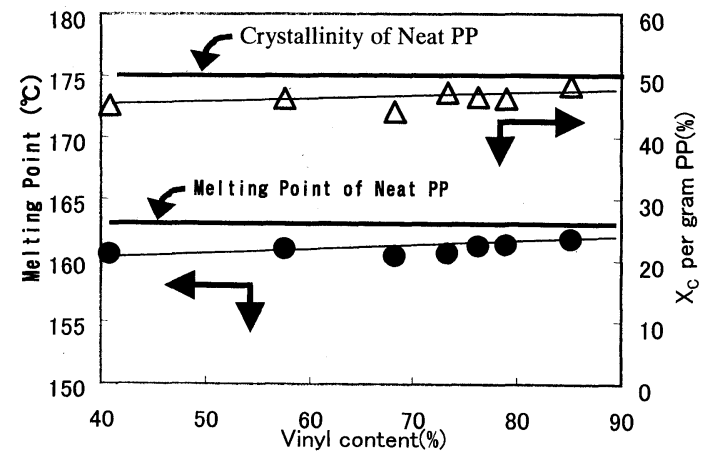

Fig.4 Plot of melting point (left : filled circle) and crystallinity per gram $\mathrm{PP}$ (rigth : open triangle) against the vinyl content of the SEBS in PP/SEBS $=70 / 30$ blends.

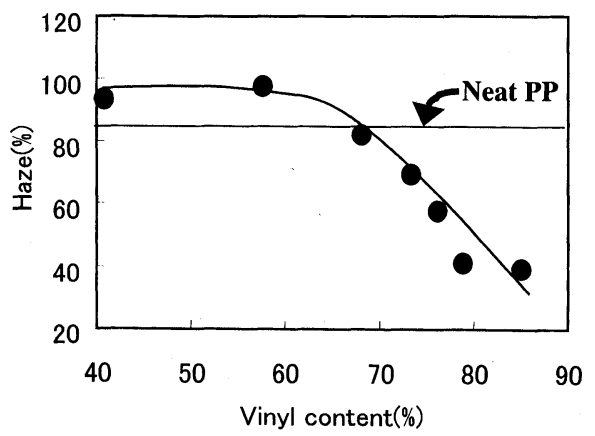

Fig.5 Plot of haze against the vinyl content of the SEBS in $\mathrm{PP} / \mathrm{SEBS}=70 / 30$ blends.

加するにつれて増加する傾向があり，高ビニル SEBS の $X_{C}$ はPP単体と同等であった。このことから高ビニル SEBS の構造がPPの結晶量には影響を与えないことが分かる.

\section{3 透明性}

Fig. 5 にPP/SEBS ブレンドの HAZE 测定結果を示す. HAZEはビニル含量に依存し，ビニル含量が70\%以下の PP/SEBSブレンドではPP単体よりも透明性が悪化した。 これは，PP中にSEBSが可視光を散乱する大きさで分散 したことを示す。それに対し，ビニル含量が70\%以上の $\mathrm{PP} / \mathrm{SEBS}$ ブレンドでは PP 単体よりも透明性が向上した. $\mathrm{PP}$ 単体の HAZEはPP 結晶の高次構造, つまり球晶の成 長に起因する。したがって，ビニル含量が $70 \%$ 以上の 


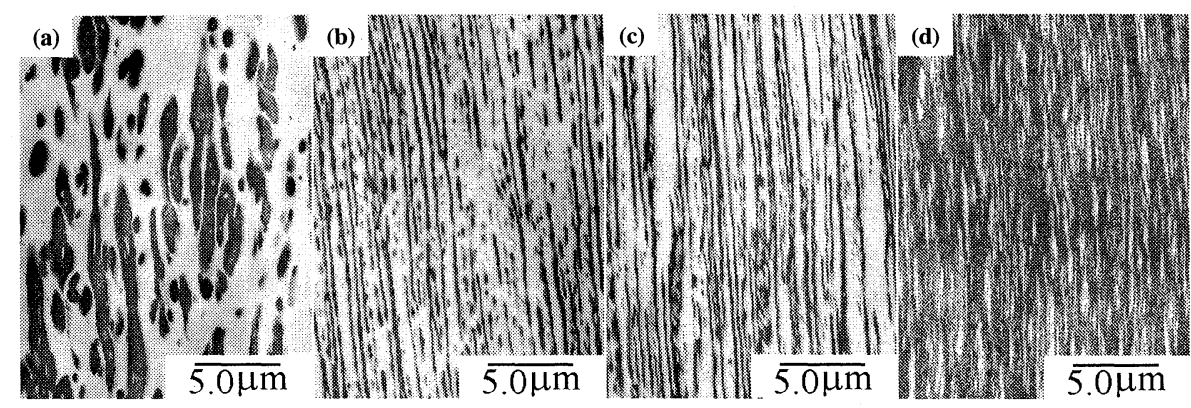

Fig.6 TEM images of PP/SEBS $=70 / 30$ blends stained with $\mathrm{RuO}_{4}$ The vinyl contents of the SEBS were (a) $41 \%$, (b) $68 \%$, (c) $73 \%$, (d) $85 \%$.

SEBSは, PP と部分相容して可視光の波長以下のオーダ 一でPP中に分散し，同時に結晶量は減らさずにPP 結晶 の成長を阻害して微細化する効果があると考えられる.

\section{4 モルフォロジー}

Fig. 6 にPP/SEBS ブレンドの TEM 観察結果を示す. SEBSのビニル含量の増大とともにブレンド中のSEBSの 分散状態が微細化しており，ブレンドの相容性はSEBSの ビニル含量とともに大きくなると示唆された.

また, SEBSのビニル含量が50\%以下の領域では明るく 見えるPPが連続相を形成し，70\%以上の領域ではSEBS が連続相を形成し，相分離構造が反転した. Fig. 7 にビニ ル含量 $85 \%$ で観察される黒い連続相の拡大図を示す. DSC 測定のPP 結晶量と PP/SEBS $=70 / 30$ の重量比とを考 慮すると，黑い連続相の中に見える未染色の明るい部分は 微細化した (10nmオーダー) PP 結晶がナノオーダーで分散 していると示唆される.

\section{5 耐溶剤性}

SEBS 単体はビニル含量によらずトルエンに溶解する. しかし, PP 単体, いずれのビニル含量の PP/SEBSブレン ドも表面状態の変化は目視で観察されなかった。これは高 ビニル含量SEBSではSEBSが連続相になっているにもか かわらず，耐油性があるのはナノオーダー分散したPP 結 晶がSEBSの耐溶剤性を向上したと示唆される.

\section{6 動的粘弾性}

$\mathrm{PP} / \mathrm{SEBS}$ の相容性についてはDMA 測定で得られる $\tan$ $\delta$ の温度依存性の変化から再検証した. Fig. 8 にPP単体 と PP/SEBS41, PP/SEBS79のDMA曲線を示した.PP単

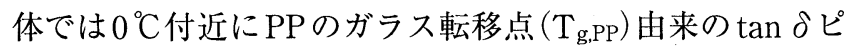
ークだけが現れた.PP/SEBS41ではSEBSのEB部のガラ 久転移点 $\left(\mathrm{T}_{\mathrm{g}, \mathrm{SEBS}}\right)$ 由来のピークが- $60{ }^{\circ} \mathrm{C}$ 付近に更にもう 1 本現れ， $\mathrm{T}_{\mathrm{g}, \mathrm{PP}}$ は変化なかった. PP/SEBS79ブレンドで は, $\mathrm{T}_{\mathrm{g} . \mathrm{PP}}$ のピーク位置が低温側にシフトするとともに, ビニル含量が増大するにつれて高くなる $\mathrm{T}_{\mathrm{g}, \mathrm{SEBS}}$ が重なり,

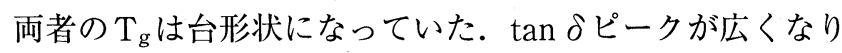
重なることから，PPの非晶部とSEBSの EB部とが相容し て，界面相を増大させると推定される。

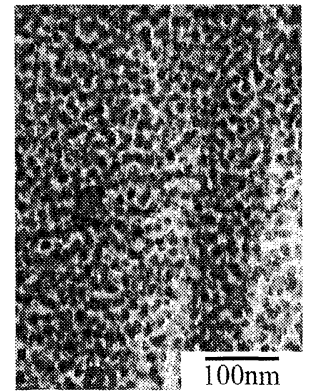

Fig.7 TEM image of PP/SEBS85 $=70 / 30$ blends stained with $\mathrm{RuO}_{4}$.

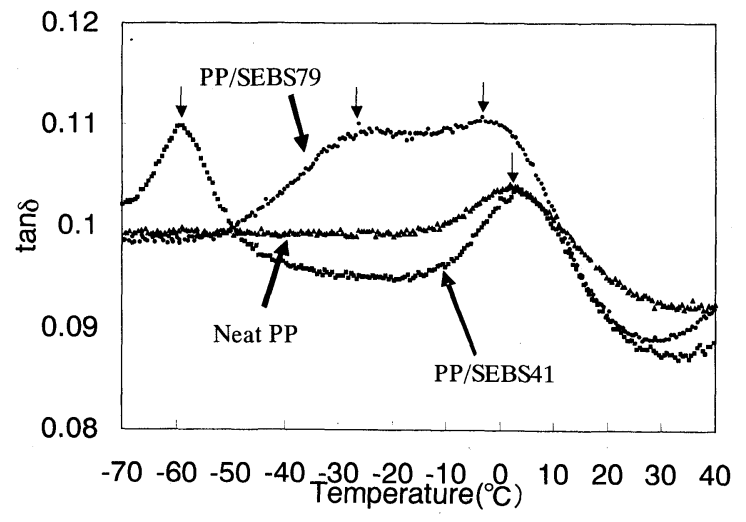

Fig.8 Plots of loss tangent against temperature for PP, $\mathrm{PP} / \mathrm{SEBS} 41=70 / 30$, and PP/SEBS79 $=70 / 30$ blends

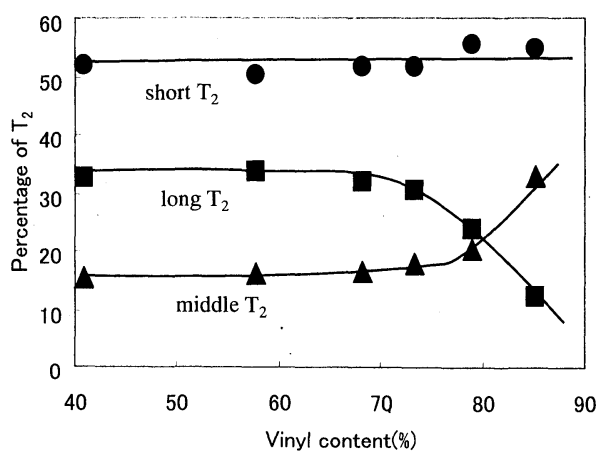

Fig.9 Percentage of long, middle, and short $T_{2}$ versus the vinyl contet of the SEBS in PP/SEBS blends.

なお，ピーク位置のシフトおよび部分的重なりはビニル 含量が79\%以上でのみ観察された。 


\section{7 パルス NMR 測定結果}

界面相の割合を測定するために，パルス NMRでの ${ }^{1} \mathrm{H}$ 核 の緩和挙動を求めFig. 9 に示した. 本ブレンド系では，い ずれの試料も緩和時間が 3 種の成分から構成されており, $\mathrm{T}_{2 \mathrm{~S}}, \mathrm{~T}_{2 \mathrm{M}}, \mathrm{T}_{2 \mathrm{~L}}$ はそれぞれ, PP結晶相, PP 結晶相と PP 非晶相との界面相又はPP非晶相と SEBS との界面相, PP 非晶相に対応する ${ }^{12)}$ と考えられる。ビニル含量が $70 \%$ 以 下では 3 つの緩和時間成分はいずれもビニル含量には依存 せずほぼ一定であった。ビニル含量が $79 \%$ 以上の $\mathrm{PP} / \mathrm{SEBS}$ ブレンドでは PP 非晶相に対応する $\mathrm{T}_{2 \mathrm{~L}}$ の分率が 減少し, PP非晶相と SEBS との界面相等に対応する $\mathrm{T}_{2 \mathrm{M}}$ の割合が増大した。これは，ビニル含量が $79 \%$ 以上の SEBSはPP との相溶性が増加していることを示唆してお り, DMA 測定結果とも一致した。

\section{4. 結}

論

1 ） $\mathrm{PP} / \mathrm{SEBS}$ ブレンドの相容性はSEBSのビニル含量 に依存し，相分離構造の分散状態はビニル含量が高いほど 微細化した。

2 ）相分離構造はビニル含量で 2 つの領域に分けられ, ビニル含量が70\%以下のSEBSはPP中に分散相を形成し た.ビニル含量が $79 \%$ 以上の高ビニル SEBSでは，PP非 晶相と部分的に相容して界面相を形成した.

3 ） PP/SEBSブレンドの融点および結晶化度はビニル
含量に依らずPP単体と同等で，高ビニル SEBSは主にPP 結晶の高次構造を変化させると示唆された.

4） PP結晶を微細化してPP微結晶に補強された連続相 を形成するために，引張特性，透明性を向上させるが，耐 溶剂性を低下させないと解釈できた。

\section{引用 文 献}

1) Coran, A. Y. : Handbook of Elastomers-New Development and Technology, Mercel Decker, New York (1988)

2 ) Morris, H. L. : Handbook of Thermoplastic Elastomers, Van Nostrand Reinhold, New York (1979)

3 ) Hashiguchi, Y., Goshima, K., Shibata, T., Teramoto, T., Mawatari, M. : Japanese Patent, JP-A-3-72512

4 ) Yanagisawa, S. : Polyfile, 29(8), 67 (1992)

5 ) Ishikawa, K., Goto, K., Hashiguchi, Y., Takemura, Y. : Polymer Prepr., 42, 1163(1993)

$6)$ Bates, F. S., Kumar, A., Schulz, M. F. : J. Polym. Sci., Polym. Phys., 33, 1423 (1995)

7 ) Weimann, P. A., Jones, T. D., Hillmyer, M. A., Bates, F. S., Londono, J. D., Melnichenko, Y., Wignall, G. D., Almdal, K. : Macromolecules, 30, 3650 (1997)

8 ) Otuka, N., Yang, Y., Saito, H., Inoue, T., Takemura Y. : Polymer, 39, 1533(1998)

9 ) Nakafutami, H., Yonezawa, J., Kato, K., Suda,Y. : Polym. Prepr Jpn, 47, 2928(1998)

10) Kodama, K., Toyoda, N., Isobe, C., Morikawa, A., Takeuchi, M., Hattori, I. : Nippon Gomu Kyokai Prepr. 59(2001)

11) Brandup, J., Innergut, E. M. : Polymer Handbook, Interscience New York (1965)

12) Nishi, T.: Kobunshi, 31, 993(1982)

\section{本会発行出版物ご案内}

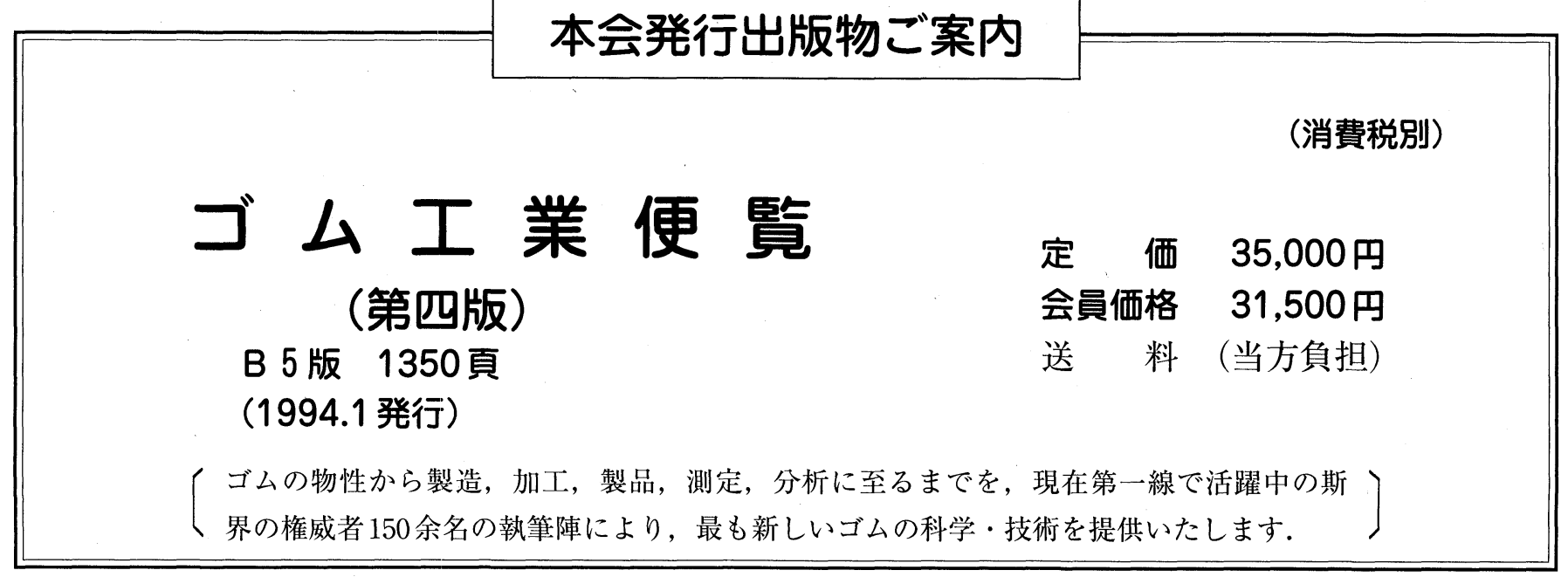

* お申込の場合は，必要事項(送付先住所，勤務先，氏名，電話番号など)をご記入のうえ， FAXしてください. 